\title{
ANÁLISIS DOGMÁTICO DE LOS TIPOS DE ABORTO EN EL PROYECTO DE CÓDIGO PENAL ARGENTINO 1
}

\author{
DOGMATIC ANALYSIS OF THE TYPES OF ABORTION IN THE DRAFT \\ ARGENTINE PENAL CODE
}

\author{
Por Gustavo Ispani ${ }^{(*)}$ \\ Gustavo Rodríguez Fernández ${ }^{(* *)}$ \\ María Marta Schianni ${ }^{(* * *)}$
}

\begin{abstract}
Resumen
En este acápite de la presentación se analizarán las figuras delictivas relativas al aborto en el "Proyecto de reforma integral del Código Penal" elaborado por la Comisión reformadora creada por el Decreto Presidencial 103/2017. En pos de cumplir con ese objetivo, se describirá el delito de aborto, circunstancias agravantes, las diferentes especies de interrupciones del embarazo impunes, el aborto preterintencional, el aborto practicado por la mujer y las lesiones al feto. En cada uno de los casos, intentaremos fijar una posición de acuerdo a nuestro enfoque sobre el tema.
\end{abstract}

Palabras claves: Aborto. Embarazo. Ser. Protección. Impunidad. Preteintecionalidad. Lesiones.

Abstract: In this paragraph, will be analyzed abortion crimes in the "Proyecto de modification del Código Penal de la Nación Argentina" (Draft amendment of the Penal Code of the Argentine Nation), that is the subject of study. In pursuit of meeting that propouse, will be described the abortion crime, aggravating circumstances, the different species of unpunished pregnancy interrumptions, the preterintencional abortion, abortion performed by the woman and and injuries to the fetus. In each of the cases, we will try to set a position according to our opinion on the subject.

Keywords: Abortion. Pregnancy. Being. Protection. Impunity. Preterintentionality. Injuries.

${ }^{1}$ Artículo recibido el 5 de agosto de 2020 y aprobado para su publicación el 17 de septiembre de 2020.

(*) Abogado y Doctor en derecho por la Universidad Nacional de Córdoba. Vocal de la Cámara $3^{\mathrm{a}}$ en lo Criminal de la Ciudad de Córdoba. Director del Instituto de Derecho Penal de la Universidad Católica de Córdoba. Profesor titular por concurso en la Universidad Católica de Córdoba Facultad de Derecho y Ciencias Sociales en la materia Derecho Penal Parte Especial y Profesor en la Facultad de Derecho y Ciencias Sociales de la Universidad Nacional de Córdoba en Derecho Penal 2 - Parte Especial.

(**) Abogado y Especialista en Derecho Penal (UNC-UNL). Profesor Titular Interino Derecho Penal Parte Especial Facultad de Derecho, Universidad Católica de Córdoba, Profesor Ayudante Derecho Penal I Facultad de Derecho y Ciencias Sociales Universidad Nacional de Córdoba, Miembro del Instituto de Derecho Penal de la Universidad Católica de Córdoba, Vocal de Cámara $9^{\text {a }}$ en lo Criminal de la Ciudad de Córdoba.

(***) Abogada y Especialista en Derecho Penal de la Universidad Nacional de Córdoba. Profesora Adjunta de Derecho Penal Parte Especial de la Facultad de Derecho Universidad Católica de Córdoba. Miembro del Instituto de Derecho Penal de la Universidad Católica de Córdoba. Fiscal Federal de $1^{\text {a }}$ Instancia de Villa María, Córdoba. 


\section{(1) (1) (9)}

Artículo publicado bajo Licencia Creative Commons Atribución-No Comercial-Sin Derivar. (C) Universidad Católica de Córdoba

DOI http://dx.doi.org/10.22529/rfd.2020(3)01 


\section{Aborto $^{2}$}

\section{I.1. Figuras básicas.}

\section{I.1.a) Concepto. Bien jurídicamente protegido.}

En esta sección del trabajo, debemos analizar dogmáticamente los tipos penales, siempre de acuerdo a las modificaciones impetradas en el Proyecto de Código Penal de la Nación Argentina 20183. Pero antes de ingresar al articulado propiamente dicho, vamos a dar las nociones generales de este delito.

En primer lugar vamos a aproximarnos a un concepto jurídico de aborto diciendo que consiste en la interrupción de la gestación del ser en cualquier tiempo y antes que el feto sea viable (18o días), con o sin expulsión del vientre materno.

Por otro lado, la ciencia médica nos proporciona una definición en la que establece que el aborto se da cuando: "se produce la expulsión anticipada o prematura del feto".

El bien jurídico protegido -que ya fue desarrollado en extenso en otra apartado de esta presentación-, es la vida del ser humano concebido, pero no nacido. La pregunta que sigue lógicamente es a qué se considera ser humano concebido. Nuestro Código Civil en su art. establece que hay vida humana desde la concepción. $\mathrm{Y}$, como se verá más adelante, los tratados internacionales firmados por nuestro país en los que se trata esta temática y que tienen categoría constitucional según el art. 75 inc. 22 de la Constitución. Nacional (C.N), también protegen la vida humana a partir de la concepción.

\section{I.1.b) Diferentes tipos de teorías relativas al momento a quo} desde el cual se inicia la protección penal de la vida.

Fecundación: La protección penal comienza desde que el espermatozoide ingresa en el ovulo y se forma el cigoto, ya que desde ese instante existe un nuevo ser con su carga genética propia (tiene sus propios 46 cromosomas). Esta es la que sigue la Corte Suprema de Justicia de la Nación

\footnotetext{
${ }^{2}$ Aporte elaborado por el Dr. Gustavo Ispani.

3 Proyecto elaborado por la "Comisión para la reforma del Código Penal de la Nación", creada por decreto $103 / 2017$
} 
(CSJN) en el fallo conocido como Portal de Belén, como también por doctrina tradicional y más representativa a nivel nacional Nuñez, Soler, Reinaldi

Singamia: Entre dieciocho y veinte horas después de la penetración el espermatozoide en el ovulo se produce la unión de los pronúcleos de las células femeninas y masculinas, transmitiéndose la información genética y creándose una nueva célula (cigoto).

Anidación: Entienden que existe vida desde que el óvulo fecundado, luego de su viaje por el endometrio, se instala en el útero materno. Esto ocurre aproximadamente entre el séptimo y el día catorce de evolución.

Sistema nervioso central: Van más allá y entienden que hay vida desde que se forma el sistema nervioso central, lo que sucede entre el día quince y cuarenta posterior a la fecundación.

Ahora bien, el quid de la cuestión reside en determinar cuál es el momento a quo y el tiempo final hasta el cual se puede ser sujeto pasivo de este delito. En definitiva, desde que momento el derecho penal protege al ser humano.

En primer término es importante aclarar las diferentes denominaciones que puede recibir el ser humano dentro del vientre materno. Aunque no existe unanimidad en cuanto al tiempo, al ser gestado o nuevo ser que surge a partir de la concepción y hasta aproximadamente el tercer mes de vida se lo denomina embrión, y recién a partir de ese momento y hasta el nacimiento se lo denomina feto. Para que quede claro, embrión y feto son denominaciones diferentes, pero que se refieren siempre al ser humano, solo que en diferentes momentos de una misma evolución.

La concepción o fecundación queda perfeccionada o consumada en el instante en que se genera la unión del óvulo con el espermatozoide. Sobre esto no existe discusión. Antes que se produzca esto, no existe nada más que un óvulo o un espermatozoide.

Es importante hacer constar que, la protección del ser humano podría comenzar inclusive antes de ese momento. Repárese que el 18 de octubre del año 2012 el Tribunal de Justicia de la Unión Europea (UE), emitió la sentencia -asunto 
C34/10-4, en el que entre otras cosas declaró que en la protección jurídica de las investigaciones biotecnológicas debe interpretarse que: "constituye un embrión humano todo óvulo humano a partir del estadio de la fecundación, todo ovulo humano no fecundado en el que se haya implantado el núcleo de una célula humana madura y todo óvulo no fecundado estimulado para dividirse $y$ desarrollarse mediante partogénesis”.

Esto tiene que ver con la antigua discusión en la que se planteaba que la condición de embrión humano se daba solo a partir de la fecundación, que era el principal punto en el que se aferraban los partidarios de las técnicas de reproducción asistida extracorpóreas. En términos simples, esta declaración lo que hace en definitiva, es considerar al ser humano biológicamente un pasito antes de lo que se entendía anteriormente, esto es, en las diferentes etapas del desarrollo embrionario inclusive hasta el óvulo humano no fecundado. Esto viene como consecuencia de que el óvulo humano tiene la capacidad de reprogramarse y desarrollar el proceso embrionario sin la presencia del espermatozoide que la fecunde (partogénesis).

Esta sentencia no es ecuménica, pero si retrae el plano de discusión acerca del momento en el que debe comenzar a considerarse la existencia del ser humano, ubicándolo en un tiempo anterior a la fecundación y con fundamentos científicos sólidos. Con lo cual, sin si quiera tomar partido a favor o en contra de esta declaración, lo que si nos debe quedar claro es que sin dudas después de la concepción existe un ser humano, y tiene siempre el mismo significado aun cuando cambie de nombre en sus diferentes etapas de gestación o de desarrollo de vida. Vale decir que se es ser humano tanto en el tiempo embrionario, fetal o posnatal, niño, adulto, etc.

El principio universal descubierto hace veintiséis siglos por Parménides 5 gran filósofo griego, establece que el ser es y el no ser, no es, y al que los lógicos llaman principio de identidad: "nada puede ser y no ser al mismo tiempo".

\footnotetext{
4 Ballesta Francisco José "Que es un embrión humanos - Una respuesta desde la bioética". Periódico Católico Encuentro. Enero 2012 Roma, Italia. 5 Manuel Garcia Morente "Lecciones preliminares de filosofía”. Ed. Losada. Pag. 83. Julio 2005. 
Entonces, si estamos en presencia de un óvulo humano, el que luego de la concepción pasa a ser un embrión, para después pasa a ser un cigoto que se anida en el útero, el mismo que a partir del tercer mes se lo va a llamar feto, para luego pasar a ser un prenatal y por último a nacer y desde allí ser una persona de existencia visible, significa que siempre estamos hablando de lo mismo, de un ser humano, solo que en diferentes etapas.

Éste es un ser único y por consiguiente distinto e independiente a los demás seres, inclusive de su madre, dentro de la cual solo crecerá para cumplir con su desarrollo vital natural, con excepción claro está de los desarrollados por partogénesis.

Lo expresado en último término vale como respuesta a aquellas teorías ${ }^{6}$ que sostienen que el feto es lo tutelado, y la vida humana depende de la persona que lo gesta y que tiene la posibilidad de decidir sobre la vida de esa persona, porque en ese momento forma parte de su propio cuerpo.

Es que, en primer lugar utilizan de manera equivocada la palabra feto, cuando en realidad es embrión -ya explicado-. Por otro lado, no es cierto que ese ser humano forme parte del propio cuerpo de la madre, toda vez que, además de que va en contra de un principio tan básico y simple como el de identidad, podemos decir sin temor a equivocarnos, que se trata de otro ser humano, tan independiente de su madre, que puede gestarse sin la presencia de ésta, como en los casos de fecundación in vitro7. En este fallo que no es condicionante para nuestro país, debido a que no fuimos parte en proceso, se establece la tesis de que la concepción se produce con la anidación del cigoto en el vientre de la madre, pero solo en los casos de partogenesis. De allí que algunos sostengan y hagan extensivo este momento a la anidación en los embarazos producidos dentro de la gestante ${ }^{8}$.

\footnotetext{
${ }^{6}$ Crespo Alvaro. "El aborto y la dignidad de la vida humana: análisis crítico de las propuestas despersonalizadoras y despenalizadoras" Año 2020. Trabajo presentado en el marco de los encuentros realizados en el Instituto de Derecho Penal durante el año 2019.

7 “Artavia Murillo y otros c. Costa Rica” (28/11/2012). Corte Interamericana de Derechos Humanos

${ }^{8}$ Fabian Balcarse "Lecciones de derecho Penal” Tomo I Pag. 198/199, Lerner 2da Ed. Córdoba 2020
} 
Podemos decir entonces que la determinación del momento exacto en que debe considerarse que un ser ha sido concebido se centra entre, la concepción propiamente dicha unión óvulo-espermatozoide -la sostenida por nosotros- y el momento de la anidación de la mola en el útero, pero no más allá de este período.

\section{I.1.c) Diferentes tipos de aborto provocado.}

Por envenenamiento salino: Es un método que se utiliza después de las dieciséis semanas de embarazo. Consiste en extraer el líquido amniótico dentro de la bolsa que protege al bebé. Se introduce una larga aguja a través del abdomen de la madre, hasta la bolsa amniótica y se inyecta en su lugar una solución salina concentrada. El bebé ingiere esta solución que le producirá la muerte, doce horas más tarde, por envenenamiento, deshidratación, hemorragia del cerebro y otros órganos. Esta solución salina produce quemaduras graves en la piel del bebé. Unas horas más tarde, la madre comienza "el parto" y da a luz un bebé muerto o moribundo, muchas veces en movimiento.

Aborto por succión: Es el método más utilizado en los países desarrollados en donde, aproximadamente, el 95\% de los abortos se realizan de esta manera. Consiste en insertar en el útero un tubo hueco que tiene un borde afilado. Una fuerte succión (veintiocho veces más fuerte que la de una aspiradora casera) despedaza el cuerpo del bebé que se está desarrollando y la placenta, absorbiendo el producto del embarazo. Luego, se introduce una pinza para extraer el cráneo que suele no salir por el tubo de succión.

Aborto por dilatación y curetaje: Consiste en utilizar una cureta o cuchillo provisto de una cucharilla filosa en la punta, con la que se va cortando al bebé en pedazos con el fin de facilitar su extracción por el cuello de la matriz con ayuda de los fórceps. Durante el segundo y el tercer trimestre del embarazo, el bebé ya es demasiado grande para extraerlo por succión, por lo que se usa este método.

" $D \& X$ " a las 32 semanas: es el método más cruento, también conocido como nacimiento parcial, se usa cuando la fecha de parto se encuentra próxima, después de haberse dilatado el cuello uterino durante tres días. Se introducen 
pinzas con las que se agarran las piernas del bebé y se extrae parcialmente el cuerpo, dejando la cabeza dentro del útero dado que es muy grande para ser extraída intacta. Por ello, el abortista entierra tijeras en la base del cráneo del bebe y las abre para ampliar el orificio. Seguidamente, inserta un catéter y extrae el cerebro mediante succión. Todo ello, provoca la muerte del bebé, haciendo que su cabeza se desplome, luego de lo cual se extrae la criatura y se corta la placenta.

Mediante prostaglandinas: Consiste en el uso de un fármaco que provoca un parto prematuro, generalmente a partir de la mitad del embarazo hasta las últimas semanas. Puede causarle graves daños a la madre y su principal "complicación", es que a veces el bebé nace con vida. Recientemente, las prostaglandinas se han usado con la pasilla RU 486 (píldora abortiva) para aumentar la efectividad de aquellas.

\section{I.1.d) Recepción constitucional y legal del derecho a la vida.}

El preámbulo de nuestra $\mathrm{CN}$ es promover el bienestar general. En 1869 se dicta el $\mathbf{C C}$ que decía que son personas por nacer, las que no habiendo nacido están concebidas en el seno materno. Asimismo, en el art 70 se establecía que, desde la concepción en el seno materno comienza la existencia de las personas y antes de su nacimiento pueden adquirir algunos derechos como si ya hubieran nacido.

Comité jurídico de la Unión Panamericana: "Toda persona tiene derecho a la vida. Este derecho comprende el derecho a la vida desde el momento de la concepción, el derecho a la vida de los incurables, los imbéciles o los insanos".

En 1989, la Ley 23.480 ratifica la Convención sobre los Derechos del Niño. Argentina propuso (y fue aceptada) una declaración interpretativa. En su art. $1^{0}$ se establece que se entiende por niño todo ser humano desde la concepción hasta los 18 años. Se prioriza el interés superior del niño. En 1994 dicha convención se incorporó con jerarquía constitucional (art 75 inc. 22). 
CADH, Pacto de San José de Costa Rica: art 1: "para los efectos de esta convención, persona es todo ser humano". El art. 4 sostiene: "Toda persona tiene derecho a que se respete su vida. Este derecho estará protegido por la ley en general, a partir del momento de la concepción. Nadie puede ser privado de la vida arbitrariamente".

Antes de la reforma constitucional del año 1994, Bidart Campos decía "En nuestro derecho, aunque ninguna norma infra constitucional hiciera arrancar el derecho a la vida desde la concepción, entendemos que el aborto lo viola y que abortar -con o sin ley que lo autorice- es inconstitucional. Ni siquiera el aborto por motivos terapéuticos, eugenésicos, sentimentales, podría purgarse. No llegamos a decir que la Constitución obliga a penalizar el aborto mediante ley pero sí decimos que cuando lo penaliza -como nuestro Código Penal- las desincriminaciones que a continuación hacen excepción a la punición aparentan revestir implícitamente el alcance de una especie de autorización legal que, en cuanto tal, si es inconstitucional"9.

\section{I.2. Desarrollo de las conductas.}

El art. 85 del Proyecto de Reforma al Código Penal establece que: "El que causare un aborto será penado: $1^{\circ}$ ) Con prisión de tres (3) a diez (10) años, si obrare sin consentimiento de la mujer. Esta pena podrá elevarse hasta quince (15) años, si el hecho fuere seguido de la muerte de la mujer.

$2^{\circ}$ ) Con prisión de uno (1) a cuatro (4) años, si obrare con consentimiento de la mujer. El máximo de la pena se elevará hasta seis (6) años, si el hecho fuere seguido de la muerte de la mujer.

El artículo conserva casi en su totalidad la redacción anterior. Solo cambia la palabra será "reprimido" que se encontraba en el anterior articulado, por "penado", una modificación que nos parece correcta.

\footnotetext{
9 Bidart Campos German "Tratado elemental de Derecho Constitucional”, Ed. Ediar, Buenos Aires,
} 1998, Tomo III, página 177 
También en el primer inciso, cuando describe la elevación de la escala penal por producción de la muerte de la mujer (esta pena podrá elevarse hasta quince años), no especifica -en el inciso $2^{\circ}$ si lo hace-, si la mayor cuantía de la misma se debe practicar en el mínimo y en el máximo, o solo en la parte inferior o superior de la escala punitiva. Se entiende que debe aplicar en el máximo de la pena a aplicar.

Sujeto activo de este delito puede ser cualquier persona, mientras que sujeto pasivo únicamente puede ser el gestado con vida.

El tipo objetivo consiste en la interrupción del embarazo con resultado material muerte de lo que podríamos denominar indistintamente embrión o feto, depende del momento en que se lo practique. Pero como vimos, en todos los tratados internacionales e inclusive en nuestro Código Civil a este ser se denomina persona, persona humana o persona por nacer. Vale decir que el ataque tiene que estar dirigido a matar al ser en gestación.

La gravidez puede ser fruto de la fecundación natural o artificial, pero siempre dentro de las entrañas de la madre. Aquí encontramos una primera dificultad que desde ya queremos dejar marcada, en cuanto a que no se incluye dentro de las gestaciones a las fecundaciones producidas in vitro. Vale la pena recordar en este punto, lo resuelto por el Tribunal de Justica de la UE referenciado más arriba.

Los requisitos corpóreos de la figura pueden clasificarse en tres:

a) Existencia de un embarazo.

b) Subsistencia del embrión o feto con vida.

c) Muerte provocada del embrión o feto, a raíz de maniobras realizadas o medios utilizados al efecto y solo de dos formas posibles: 1) producir la muerte de la persona por nacer dentro del seno materno; o 2) provocar la expulsión anticipada de la misma y de esta manera causar su deceso.

El aborto puede causarse por cualquier medio. Existe en el tipo un elemento normativo de carácter jurídico, cuando agrava la conducta cuando el autor obra sin consentimiento. 
Respecto a este último tópico, tiene que haberse ocasionado la salida del feto del claustro materno y morir inmediatamente por la imposibilidad natural de supervivencia. En caso de que nazca con vida y luego se lo mate, la conducta constituye un homicidio. Por último, si hubiera existido la intención de abortar, el feto nace con vida sin más, podría quedar en grado de conato.

Con relación al tipo subjetivo, la figura exige que el o los sujetos activos del delito actúen con dolo. Solo para adelantar, decimos que en el Proyecto se mantiene la posibilidad de ocasionar un aborto de manera preterintencional, y además hace una importante modificación ya que pregona la contingencia de capturar la conducta por culpa en el proceder imprudente o negligente del autor, que veremos más adelante.

Para las acciones previstas en primer término, solo se admite el dolo directo o de propósito, que implica conocimiento de la existencia del embarazo y voluntad de causar la muerte del feto.

Esta figura admite todos los grados de participación criminal dispuestos en nuestro código. Deberá ponerse especial atención en cuanto a las actividades desplegadas para determinar su calidad.

Se trata de un delito de acción, pluriofensivo y de resultado instantáneo, por tanto admite la posibilidad de la tentativa, la que se da cuando a pesar de las maniobras desplegadas, el feto sigue con vida. Cuando las maniobras han sido inidóneas para poder realizarlo, se trata de un delito imposible. Es un crimen que da lugar a la acción pública.

Por último, las razones por las cuales este tipo delictivo tiene una punición inferior tanto en el mínimo como en el máximo de la escala respecto al homicidio, viene de tiempos inmemoriales y tiene que ver con que este ser constituye una vida en gestación y no una ya adquirida. Claro está que el extremo superior de la gradación del aborto supera largamente el mínimo de la del segundo, con lo cual pueden darse abortos con pena superior a un homicidio. En consonancia con esta merma en las penas, también el infanticidio preveía un monto inferior en su escala punitiva. 


\section{I.2.a) Especies de aborto.}

Se habla de un aborto espontáneo cuando la muerte del gestado es producto de alguna anomalía o disfunción no prevista ni deseada por la madre. Mientras que el aborto provocado se da cuando la muerte del ser es procurada de manera doméstica, química o quirúrgica.

El aborto provocado puede ser causado por un tercero o por la propia mujer. Está claro que del hecho se tiene que producir la muerte de la madre, lo que despeja toda duda respecto a que de la muerte del gestado se produzca el óbito de la de la mujer embarazada. Con esto queremos decir que la muerte de la mujer puede y debe provenir tanto de las maniobras abortivas practicadas antes de la consumación del aborto, es decir, aborto tentado, cuanto de las actividades propias del aborto ya provocado. Con esta calificante se intenta proteger no solo la vida de la mujer, sino también su derecho a ser madre.

Nada se ha dicho respecto a las lesiones previstas en los artículos 90 y 91 del Código Penal. Pensamos que por la amplitud dispuesta en la escala penal, este tipo de resultados están implicados.

Las teorías que plantean que se puede interrumpir la vida del gestado con posterioridad a la concepción y que esa conducta no sea penada, solo lo hacen para el caso de que exista la voluntad de la madre en querer practicarlo, basándose en que ese ser todavía no es persona humana independiente de ella. Ahora bien, cuando se practica el aborto sin el consentimiento de la madre, "¿Qué es lo que se mata si no constituye una persona independiente de la madre?. La pregunta es: ¿Qué se estaría atacando con esa acción?

Respecto al consentimiento, este debe ser expreso o tácito, pero nunca presunto, y se agrava solo si muere la mujer. Cuando el aborto es causado por la propia mujer, la tentativa no es punible. 
Puede darse como resultado de las maniobras abortivas, que muera la mujer y no el feto. En ese caso, la conducta podrá quedar atrapada en alguna de las variantes del homicidio, dependerá de qué tipo de acción realizó el sujeto activo.

\section{I.2.b) Circunstancia Calificante}

El art. 86 del Proyecto de reforma del C. Penal, establece que: "1. Se impondrán las penas establecidas en el art. 85 e inhabilitación especial por doble tiempo de la condena a prisión, a los médicos, cirujanos, parteras ofarmacéuticos que abusaren de su ciencia o arte para causar el aborto o cooperen a causarlo”.

$\mathrm{El}$ art. 86 del C.P. del Proyecto, tiene una modificación sustancial en el segundo inciso, segundo supuesto, que desarrollaremos más adelante. Como cambios no significativos, podemos mencionar que el artículo cambia la alocución incurrirán por el de se impondrá, respetando la sistemática elegida al tiempo de decidir la carga punitiva a aplicar.

Todo lo descripto en el desarrollo conceptual de figura dispuesta en el art. 85 del C. Penal, se mantiene inalterable en esta conducta, con excepción del sujeto activo que en esta primera parte del artículo está determinado, ya que solo pueden ser los que están mencionados en la norma -médicos, cirujanos, parteras o farmacéuticos que abusaren de su ciencia o arte para causar el aborto o cooperen a causarlo-. Se mantienen las circunstancias tipificantes para el caso que el delito fuera practicado por un médico o algún idóneo en el arte de curar, para los cuales está estipulada una pena de inhabilitación especial por el doble tiempo de la condena.

Este proyecto de modificación sigue sin corregir lo descripto en último término "cooperaren a causarlo". En primer lugar aplica la misma escala penal al autor que a los partícipes. Y además, la colaboración que se preste -cooperar-, puede ser resuelta y penada de acuerdo al instituto de la participación criminal como en cualquier otro hecho. 
Por otro lado, si bien el tipo subjetivo describe que el sujeto tiene que actuar con dolo directo, existe un elemento subjetivo del tipo abusaren de su ciencia o arte que fuerza el dolo y lo lleva a que se especifique.

\section{I.2.c) Abortos impunes o inculpables.}

2. El aborto practicado por un médico diplomado con el consentimiento de la mujer embarazada no es punible:

$\left.1^{o}\right)$ Si se ha hecho con el fin de evitar un peligro para la vida o la salud física o mental de la madre y si este peligro no puede ser evitado por otros medios.

$\left.2^{\circ}\right)$ Si el embarazo proviene de un abuso sexual.

Continúa con las exigencias que imponía el artículo anterior, esto es: a) médico diplomado: Criticamos acá la palabra diplomado, debido a que puede ejercitar la medicina una vez autorizado por el colegio profesional y aun no haber recibido el pergamino. Es una circunstancia tipificante que ha caído en desuso; b) consentimiento de la mujer embarazada -antes decía en cinta-, lo cual ajusta el término a estos tiempos. Claro está que no determina desde cuando se considera que una mujer está en estado de gravidez, lo que constituye un elemento normativo no jurídico y que en este caso nos remite a la legislación civil.

\section{I.2.D. Especies.}

En materia doctrinaria, históricamente existieron tres, de los cuales solo dos estaban legislados en nuestro Código Penal, a saber:

a) Terapéutico: peligro de vida de la madre. No existe en este tópico ninguna modificación y es pacífica la doctrina y la jurisprudencia respecto a la aceptación sin más del aborto, en los casos en los que la madre presente algún peligro de vida o salud de continuar con el embarazo. Solo se requerirá en estos casos del diagnóstico médico que así lo determine y como es obvio, del 
consentimiento de la madre y si esta no pudiera por alguna circunstancia, será el padre o el representante legal designado al efecto.

b) Eugenésico: violación o atentado al pudor de una mujer idiota o demente. Sin entrar en demasiados, detalles debido a que el fallo F, A.L. s/medidas autosatisfactiva que ha sido ampliamente desarrollado en otro acápite de esta presentación, ${ }^{10}$ su fundamento consiste en resguardar la pureza de la raza. Además ha tenido grandes reparos jurídicos, tantos que ha sido eliminado de los últimos proyectos de reforma.

c) Sentimental o por profanación: En primer lugar no estamos de acuerdo con la denominación dada a este tipo de aborto. Creemos más correcto hablar de un aborto por abuso sexual o a fin de evitar una tautología podría denominarse aborto por profanación.

Se da cuando el embarazo sea producto de un abuso sexual con acceso carnal. La fórmula legal utilizada en este Proyecto, es una síntesis de lo resuelto en el fallo antes indicado.

Solo agregamos, a lo que ya se dijo sobre este tema, que sería más apropiado describir la conducta diciendo que el embarazo proviene de un abuso sexual con acceso carnal. Primero, porque el término violación desapareció con las modificaciones propias de los delitos contra la integridad sexual ${ }^{11}$. $\mathrm{Y}$ además, para evitar todas las complicaciones que se ocasionaron a partir de la expresión atentado al pudor en la descripción típica actual. Además cuando el embarazo proviene de un abuso sexual, solo si se produce el acceso carnal puede originarse un embarazo, es por ello la aclaración.

Aunque excede el objetivo de este trabajo, consideramos que luego de la reforma constitucional de 1994 -art. 75 inc. 23-, debe reformularse la discusión sobre la naturaleza jurídica de las indicaciones médicas como causal de no

\footnotetext{
${ }^{10}$ Consuelo Capdevila y Guillermo Funes. "Repensando F, A.L. s/medidas autosatisfactiva: algunos aportes para el debate.”. Año 2020. Trabajo presentado en el marco de los encuentros realizados en el Instituto de Derecho Penal durante el año 2019.

${ }^{11}$ Boletín Oficial 07/03/1995. Rúbrica según ley 25087 al Título 3 del Código Penal.

REVISTA FACULTAD DE DERECHO NUMERO 32020 
punibilidad del aborto, debiéndose analizar la consistencia de considerar a las mismas como excusas absolutorias.

Es que, no compartimos la aceptación acrítica de tratar a las indicaciones médicas como causa de justificación que legitime el obrar antijurídico.

Los defensores de esta postura, sostienen a grandes rasgos que la ley autoriza a salvaguardar el bien jurídico preponderante. Entendemos que ambos bienes son de igual jerarquía, ambos son personas. La diferencia de una menor escala penal del aborto respecto del homicidio, ya fue explicado más arriba.

Entendemos que en los abortos inculpables estamos ante hechos típicos y antijurídicos, pero que gozan de inculpabilidad. A esta conclusión llegamos porque sostenemos que quienes se encuentran inmersos en las situaciones descriptas en el art. 86 del C. Penal, y deciden practicar un aborto, cometen el injusto en un estado de necesidad disculpante.

Por último, este tipo de aborto es producto de otra cuestión que debe verificarse. Es que importantes estudios realizados en Estados Unidos ${ }^{12}$, determinaron la ínfima posibilidad de embarazo en caso de abuso sexual con acceso. Esto lo agregamos solo para fortalecer la necesaria comprobación fáctica de la existencia de un abuso sexual. Con la declaración jurada, cualquiera podría aducir un embarazo violento, sin que se compruebe mínima y efectivamente esa situación, lo que a todos luces traería aparejado una desigualdad jurídica (art. 16 C.N.)

II. El aborto violento no intencional y los abortos referidos a la actuación de la propia mujer ${ }^{13}$

A fin de examinar las características de la regulación del aborto violento no intencional y de los abortos referidos a la actuación de la propia mujer en el Proyecto de reforma integral del Código Penal elaborado la Comisión para la Reforma del Código Penal de la Nación, creada por el Decreto Presidencial

${ }_{12}$ Mons. Ramón Benito de La Rosa y Carpio "Vida y aborto: Afirmaciones científicas, éticas y legales", Ed. De la Rosa, Octubre 2017.

13 Aporte elaborado por el Abog. Esp. Gustavo Rodríguez Fernández. 
103/2017 (B.O., del 14/02/2017), abordaremos en primer lugar una síntesis de las principales cuestiones desarrolladas por la doctrina con respecto a los enunciados normativos vigentes. Esto, a su vez, exigirá una referencia a los últimos proyectos de reforma que se construyeron en relación a los referidos tipos penales. Sobre esta base, previo a dar cuenta de la redacción de los nuevos enunciados proyectados, ponderaremos los alcances de la reforma; para concluir formulando sintéticamente una valoración personal al respecto.

A fin de no defraudar expectativas, por una cuestión de delimitación temática, debemos señalar que en este trabajo no nos ocuparemos sobre la consistencia o (in)consistencia axiológica y jurídica de los distintos proyectos que han intentado legislar sobre la interrupción legal del embarazo, ni tampoco sobre las implicancias del pronunciamiento de la Corte Suprema de Justicia de la Nación in re "F., A. L. s/medida autosatisfactiva" en reconocer un deber de prestación del Estado en los casos de las prácticas de aborto no punibles, contemplados en el artículo 86, incisos $1^{\circ}$ y $2^{\circ}$ del Código Penal; las que son abordados en otros de los trabajos incorporados en esta revista, y que -tal vez- en un futuro merezcan nuestro análisis.

\section{II.1.a) El aborto violento no intencional}

El artículo 87 del Código Penal reprime con prisión de seis meses a dos años, el que con violencia causare un aborto sin haber tenido el propósito de causarlo, si el estado del embarazo de la paciente fuere notorio o le constare. El referido enunciado proviene del Código de 1886, y fue mantenido por los proyectos de 1891, 1906 y 1917.

La fórmula utilizada por el legislador ha recibido tradicionalmente la denominación de "aborto preterintencional"14, requiere para su configuración la concurrencia de los siguientes elementos:

a) una mujer en estado de embarazo;

14 Soler, Sebastián, Derecho Penal Argentino, ed. Tea, Bs. As., 10ma. Reimpresión, 1992, p. 109; Nuñez, Ricardo C. Manual de Derecho Penal. Parte Especial, ed. Lerner, 4ta. Ed., Bs. As., p. 28.; Donna, Derecho Penal. Parte Especial, T.I, 4ta. ed., p. 270. 
b) el ejercicio de violencia -física o psíquica- sobre el cuerpo de la mujer. Cabe recordar que la violencia es el despliegue de una energía física por el autor, quedando comprendida en el concepto de violencia el uso de medios hipnóticos o narcóticos (arg. art. 78 del C.P.). La violencia requerida debe dirigirse en contra la mujer;

b) el estado de embarazo le debe constar al autor (conocimiento asertivo del mismo, aunque no fuera visible) o que sea notorio (manifiesto para la generalidad de los individuos, no solo para el autor);

b) la muerte del feto, vale decir, que se cause un aborto (no su tentativa) como consecuencia del empleo de violencia (relación causal entre el acto violento y el resultado muerte del feto).

La vinculación entre la acción del sujeto activo y el resultado deben regirse por los principios generales de la causalidad e imputación objetiva.

Las exigencias del tipo objetivo del referido delito no originó "ninguna discordancia ni opinión disidente" 15 , por el contrario las diferentes posiciones se generaron en lo referente a las características del tipo subjetivo del ilícito bajo estudio.

Así, para un sector de la doctrina, el artículo 87 del Código Penal prevé una especial forma de aborto culposo (PECO ${ }^{16}$, DíAZ ${ }^{17}$, ODERIGO ${ }^{18}$, RAMOS ${ }^{19}$, RIGHI ${ }^{20}$ ), ya que la violencia, aunque ilícita, no constituye en sí misma un hecho delictivo doloso y su empleo causa un resultado imprudente. Los autores que sostienen esta posición consideran que el delito preterintencional requiere la existencia de una conducta típica dolosa y un resultado imprudente, lo cual no se verifica en el delito bajo examen, pues la violencia desplegada, aunque ilícita, no constituye un delito, sino un acto penalmente intrascendente.

15 Tazza, Alejandro, Código Penal de la Nación Argentina comentado, parte especial, Rubinzal Culzoni, Santa Fe, T. I., 173.

${ }_{16}$ Peco, José, El aborto en el Código Penal, p. 133.

17 Díaz, Emilio, El Código Penal, $3^{\circ}$ ed., 1928, Buenos Aires, nº 350.

18 Oderigo, Mario Código Penal anotado, Buenos Aires, 1957, p. 122.

19 Ramos, J.P. Curso de Derecho Penal, T. V., p. 127.

${ }^{20}$ Righi, Esteban, Revista de Derecho Penal y Criminología, no 1, enero-marzo de 1969, p. 65. 
Para Ramos Mejía se trata de una hipótesis de sucesión de dolo y culpa, esto es, un primer tramo que responde a una acción dolosa (la violencia) que es lo querido por el agente, y un resultado (el aborto) que no es querido pero que ha sido producido por culpa, en este caso consciente, porque el embarazo de la víctima, conforme el enunciado típico, debe ser notorio o le debe constar al autor.

Carlos FONTÁN BALESTRA ${ }^{21}$ lo considera inicialmente aborto preterintencional, al igual que TERÁn LOMAS, NúÑEz, CARRERA y Sebastián Soler. Este último considera para sustentar su posición que el enunciado normativo contiene un hecho ilícito doloso, lo cual permite diferenciarlos de las figuras culposas. Además, la comparación de las escalas penales originarias permite descartar la previsión en la referida norma del aborto culposo, toda vez que si así fuera la muerte de un feto habría sido reprimida con la misma pena con la muerte culposa de una persona con vida humana independiente, a pesar de las diferencias punitivas que median en las modalidades dolosas de los referidos delitos ${ }^{22}$.

Bien se advirtió que tal temperamento interpretativo deja una franja neutra para el derecho penal, constituida por las conductas subjetivamente comprendidas entre el dolo cierto requerido para las formas dolosas del aborto y la preterintención ${ }^{23}$. Para zanjar dicha dificultad MOLINARIO sostuvo que la disposición legal reprime cualquier aborto producido por medios violentos, aunque éstos no vayan dirigidos a producir el resultado, concluyéndose que esa figura debería llamarse aborto violento e imprevisto 24 .

El mismo Carlos Fontán BALESTRA admite que en la figura bajo análisis también están incluidas las formas violentas de aborto cometidas con dolo eventual. Pero no porque tales modalidades puedan ser incluidas dentro de la idea de lo preterintencional, sino porque tanto los hechos cometidos en forma preterintencional como los que resultan del dolo eventual del autor, son resultados

\footnotetext{
${ }^{21}$ Fontán Balestra, Carlos, actualizado por Guillermo A.C. Ledesma, Tratado de Derecho Penal Parte Especial-, Bs. As. 1era ed., 1ra. Reimpresión, Buenos Aires: La ley, 2014, p. 228.

${ }^{22}$ Soler, Sebastián, ob. cit., p. 110.

23 Fontán Balestra, Carlos, ob. cit., p. 229.

24 Molinario, Alfredo, Derecho Penal. Segundo curso, La Plata, 1943, p. 101. 
que no se han tenido en el propósito del causar25. En esa misma línea NúÑEZ explica que "la preterintencionalidad no tiene aquí el mismo significado que en el homicidio preterintencional, porque su concepto no se atiene ni a la naturaleza del medio empleado por el autor, ni está limitado por la posibilidad de este de prever el resultado abortivo. La preterintencionalidad del aborto únicamente significa que la muerte del feto no está en el propósito del autor de la violencia. Comprende, por el contrario, la muerte del feto que al autor se le presente como resultado eventual" 26 .

Para Eusebio GómEz, las exigencias del tipo subjetivo del tipo analizado presupone un actuar doloso, pero de dolo indirecto, al considerar que debe desecharse el aborto culposo, porque el precepto legal se refiere al empleo de violencias, y si bien ellas no han respondido al propósito de causar el aborto, no podrían encuadrarse en ninguno de los supuestos de la culpa, por lo que considera que el tipo subjetivo requerido por la figura es doloso, pero de dolo indirecto ${ }^{27}$.

En tanto que Edgardo DonNa, coincidiendo con Bustos RAMírEZ, GRISOLÍA Y Politoff, señala que el aborto previsto en el artículo 87 se trata de un tipo compuesto, por un actuar doloso con respecto a la violencia en contra de la mujer, y en cuanto al aborto es aceptable tanto el dolo eventual como la culpa ${ }^{28}$.

A su turno, Ana LOMBARDI y María Noel CosTA sostienen, luego de descartar el tipo preterintencional, que el tipo objetivo "describe na sola conducta típica, esto es el aborto no constituyendo un tipo penal autónomo el despliegue de violencia por parte del agente. Por el contrario, de la lectura de la norma trasciende que la violencia es el medio para lograr el aborto"29.

Por su parte Carlos CReus y Jorge BuOMPADRE consideran que, la culpabilidad típica está descripta en forma negativa por el tipo, lo cual ha inducido a pensar en un aborto culposo y a otros en un aborto preterintencional. Ahora bien,

\footnotetext{
25 Fontán Balestra, Carlos, ob. cit., p. 230.

${ }^{26}$ Nuñez, Ricardo C., Manual de Derecho Penal, (actualizado por Víctor Félix Reinaldi), Ed. Lerner, Córdoba, p. 29.

27 Gomez, Eusebio, Tratado de Derecho Penal, T. II, Buenos Aires, 1939, p. 143.

28 Donna, Edgardo Alberto, Derecho Penal: parte especial, $4^{\circ}$ edición actualizada y reestructurada, Santa Fe, Rubinzal Culzoni, 2011, p. 271.

29 Lombardi, Ana- Costa, María Noel, Delitos contra la vida humana dependiente. En Balcarce, Fabián I., Lecciones de Derecho Penal. Parte Especial, T.I., Córdoba, 2016, p. 199.
} 
por la sola exclusión del dolo de propósito, quedan comprendidos en el tipo tanto el caso en que a la voluntad de actuar violentamente sobre la mujer se agregó la aceptación del resultado de aborto que podía producirse (dolo eventual), como el caso en que ese resultado ni siquiera estuvo presente en la mente del autor (culpa inconsciente).

Adherimos a la postura que propugna que el enunciado típico analizado abarca tanto la forma preterintencional $3^{\circ}$, como la muerte del feto que se presenta como eventual. Es que, al estar la violencia dirigida contra la mujer, no en contra el feto, no puede configurarse la forma culposa, ya que la culpa, bien dice Núñez, no es compatible con la mala intención de violentar a la mujer. Por otra parte, agregamos nosotros, si el legislador hubiera querido configurar este tipo de aborto a título de culpa, lo hubiera así tipificado expresamente, como lo hizo con otras figuras culposas. A ello debe agregarse que, la interpretación que sostiene que el aborto previsto en el artículo 87 del Código Penal es un aborto culposo quebranta el sistema de numerus clausus escogido por el legislador argentino para sancionar los tipos culposos, pudiendo así considerar la posibilidad culposa frente a cualquier delito.

La tesis del dolo directo tampoco resulta aceptable, pues no solo generaría confusión con la forma común del aborto, sino porque la propia descripción legal lo excluye de manera explícita ("sin haber tenido el propósito de causarlo", dice el art. $87)^{31}$.

De otro costado debemos señalar que la expresión "violencia" ejercida sobre el cuerpo de la mujer, como genérica que es, abarca a traumatismos o malos tratos que, por su naturaleza, no importen más mal que el causado por la mujer por el

$3^{3}$ Bien destaca Núñez que la preterintencionalidad no tiene aquí el mismo significado que en el homicidio preterintencional, porque su concepto no se atiene ni a na naturaleza del medio empleado por el autor, ni está limitado por la posibilidad de este de prever el resultado abortivo. La preterintencionalidad del aborto únicamente significa que la muerte del feto no está en el propósito del autor de la violencia.

${ }^{31}$ Buompadre, Manual de Derecho Penal; parte especial, ed. Astrea, Bs. As., 2013, p. 83. 
aborto mismo. Así las cosas, si el resultado de las violencias ejercidas trasciende en lesiones graves o gravísimas, estas concurrirán con el delito bajo examen ${ }^{2}$.

Conforme a lo ya definido el tipo penal analizado constituye un delito de acción, de resultado instantáneo (muerte del feto), de medios determinados (violencia ejercida contra la mujer embarazada) y de ofensa compleja (integridad física de la mujer embarazada y vida del nasciturus).

Por lo demás, por la propia estructura del tipo analizado la tentativa no resulta admisible.

\section{II.1.b) El aborto violento sin representación en el Proyecto de reforma de Código Penal}

La comisión reformadora dispone en el artículo 87 dos párrafos, receptando en el primero de ellos el aborto preterintencional, modificando su redacción original, en tanto que en el segundo establece y recepta el aborto imprudente.

Concretamente, y en lo que aquí interesa, el párrafo primero señala que se impondrá prisión de uno (1) a tres (3) años, al que con violencia causare un aborto sin haberse representado esa consecuencia, si el estado de embarazo de la mujer fuere notorio o le constare.

La nueva fórmula coincide con la anterior al prever como requisitos objetivos del tipo analizado la existencia de una mujer en estado de embarazo, el ejercicio de violencia sobre de ella, que se cause la muerte del feto como consecuencia de las lesiones y que el estado de embarazo fuere notorio o que le constare al autor.

Ahora bien, la Comisión modificó la legislación vigente en lo atinente al tipo subjetivo negativo del referido delito al referir "sin haber tenido el propósito de causarlo", por la fórmula "sin haberse representado esa consecuencia". Dicha modificación resulta novedosa por cuanto no estaba prevista en el Proyecto de 2006 y 2014 e impacta en la discusión que mantiene la doctrina en orden a la

$3^{2}$ Soler, Sebastián, Ob. cit., p. 110, Nuñez, Ricardo C., ob. cit., p. 29.

\begin{tabular}{llll}
\hline REVISTA FACULTAD DE DERECHO & NUMERO 3 & 2020 & Página 24 \\
\hline
\end{tabular} 
naturaleza subjetiva de la figura, conforme al texto del Código vigente y que fuera reseñada precedentemente.

De tal manera que, el nuevo tipo se construye sobre la base de una acción inicial dolosa, pues así debe entenderse el despliegue de violencia, y un resultado que el autor no se representa, quedando delineada la característica preterintencional de la figura con mayor claridad que en el texto actual.

Sin perjuicio de lo expuesto precedentemente, debe destacarse que el nuevo texto deja una franja neutra para el derecho penal, constituidas por las conductas subjetivamente comprendidas entre el dolo directo y la preterintención.

Por lo demás, y en lo referente a la pena, el Proyecto analizado prevé una escala penal de uno a tres años de prisión, siguiendo el temperamento asumido en los Proyectos 2006 y 2014, justificándose en este último Proyecto dicho aumento punitivo en que el delito analizado "tiene un contenido injusto un tanto superior al reflejado en la pena vigente (seis meses a dos años)"

\section{II.2.a) Los supuestos legales de aborto referidos a la actuación de la propia mujer}

El artículo 87 del Código Penal reprime con prisión de uno a cuatro años a "la mujer que causare su propio aborto o consintiere que otro se lo causare. La tentativa de la mujer no es punible".

La disposición contempla -sustancialmente- el aborto causado por la propia mujer, e iguala en cuanto a su tratamiento punitivo a la mujer que consintiere que otro lo causare, consagrando en el último párrafo la no punibilidad de la tentativa de aborto de la mujer embarazada.

En lo que atañe a la primera hipótesis, el hecho que sea la propia mujer embarazada la autora de su propio aborto constituye una circunstancia nuclear, pues dicha conducta se distingue sustancialmente de las demás, estableciendo consecuencias distintas en materia de participación y tentativa. 
El propio Sebastián Soler aclara que todo caso de consentimiento de la mujer está afuera de esta primera hipótesis, pues aquellos suponen la intervención de un tercero en calidad de coautor. Para que pueda hablarse de aborto propio de la mujer embarazada se requiere que sea únicamente la mujer quien lo ejecute33.

Dicho con otras palabras, el tipo requiere que la mujer realice actos de consumación del aborto, vale decir, que despliegue conductas que tengan idoneidad para producir la interrupción del embarazo, provocando la muerte del feto con o sin expulsión. Por cierto, dicha materialidad no descarta la posibilidad de actos de cooperación o ayuda por partes de terceros, la cual se resuelve mediante la aplicación de las reglas comunes de los arts. 45 y 46 del código penal.

El sujeto activo sólo puede ser la propia mujer embarazada, quien ejecuta el aborto del niño que está gestando, por lo que se ha considerado que este es un delito especial de propia mano, que no admite la autoría mediata.

El sujeto pasivo es la persona humana con vida dependiente.

El tipo subjetivo de la figura analizada se satisface de la misma manera que el aborto común, esto es, con el propósito de causar el aborto, lo cual sólo es compatible con el dolo directo. Así las cosas, cualquier acto de la mujer que no esté dirigido a causar la muerte del feto, no es punible como aborto, más allá que la mujer haya conocido la asunción de un riesgo no permitido en contra la vida del feto (v.gr., el caso que la mujer intenta suicidarse y por su actuar muere la persona que se está gestando).

En la segunda hipótesis, el artículo solo declara que le corresponderá idéntica pena a la mujer que consintiere las maniobras abortivas. Se trata del consentimiento de los artículos 85 inc. $2^{0}$ y 86 , párr. $1^{\circ}$, en cuanto este se remite al anterior.

Así las cosas, la mujer que presta su consentimiento es coautora del aborto con consentimiento causado por un tercero. La criminalización de la mujer cuando presta el consentimiento para que un tercero cause el aborto sólo se activa en los casos de abortos consumados. 
En esa misma línea BUOMPADRE destaca que la simple prestación del consentimiento sin que el tercero haya realizado actos ejecutivos, queda fuera de la punibilidad. A su vez, la retractación o revocación del consentimiento puede ser retractado hasta el momento de la consumación. Ahora bien, dicho desistimiento, tiene eficacia desincriminante sólo para la mujer, no así para el tercero que continuasen quien incurrirá en el tipo previsto en el art. 85 inc. 1 del código penal 34.

Por último, el legislador dispuso en el artículo 88 del Código Penal que " $L a$ tentativa de la mujer no es punible”.

La ley declara, entonces, impune la tentativa de aborto realizada por la propia mujer embarazada, cualquiera que fuere el carácter de ella (tentativa acabada e inacabada, tentativa idónea o inidónea, y a los casos de delito imposible - para que sigan con esa terimonología- y el delito frustrado)35.

Se trata de una excusa absolutoria establecida en su favor36, en razón de que el estrépito o la trascendencia pública produce mayor perjuicio social que la impunidad en relación a un hecho que queda en la intimidad de la mujer, y que no ocasionó un efectivo daño a la persona por nacer37.

Debe quedar claro que lo impune es que la mujer misma ha sido autora de los actos ejecutivos, siendo punible la mujer que prestó su consentimiento para que otro le causare el aborto, cuando el hecho quedó en tentativa38.

Por cierto, el delito de aborto en grado de tentativa requiere para configurarse la comprobación efectiva de la iniciación de maniobras abortivas de una mujer embarazada.

La doctrina científica es coincidente en señalar que le ley excluye también de la punibilidad de la mujer cuando en su propio hecho de tentativa haya intervenido

\footnotetext{
34 Buompadre, Jorge Eduardo, Manual de derecho penal: Parte especial, p. 83.

35 Creus, Carlos - Buompadre, Jorge Eduardo, Derecho penal. Parte especial, Astrea, 7ma. Ed., Bs. As., 2010, p. 74; Donna, Edgardo, ob. cit., p. 272.

${ }^{36}$ En sentido similar, Buompadre, Manual de derecho penal: Parte especial, p. 84. En contra Justo Laje Anaya y Enrique Gavier, quienes sostienen que "no se trata de una excusa absolutoria, cuyos efectos serían personales con arreglo a lo dispuesto en el art. 48 del C.P., sino de una excepción expresa de punibilidad, de la tentativa que comprende a ésta y al delito imposible"

37 Nuñez, Ricardo C., Tratado de Derecho Penal, T. III, Lerner, Córdoba, 1977, p. 181.

${ }^{38}$ Creus, Carlos - Buompadre, Jorge Eduardo, ob. cit., p. 74.
} 
cómplices -cualquiera sea el carácter de la complicidad-, si el hecho no deja de ser una tentativa de la mujer, y los partícipes no hayan hecho más que colaborar con ella39. En esa misma línea Ricardo C. NúÑEZ sostiene que "mientras los terceros no participen en los actos consumativos de la tentativa como autores principales, el hecho continúa siendo una "tentativa de la mujer", acreedora al beneficio legal" 40 .

\section{II.2.b) Los supuestos legales de aborto referidos a la actuación de} la propia mujer en el Proyecto de reforma de Código Penal

La comisión reformadora dispone en el artículo 88 que "se impondrá prisión de uno (1) a tres (3) años, a la mujer que causare su propio aborto o consintiere en que otro se lo causare. La tentativa de la mujer embarazada de causar su propio aborto no es punible. El juez podrá disponer que la pena se deje en suspenso o eximirla de ella, teniendo en cuenta los motivos que impulsaron a la mujer a cometer el hecho, su actitud posterior, la naturaleza del hecho y las demás circunstancias que demuestren la inconveniencia de aplicar pena privativa de la libertad".

La disposición prevista en el Proyecto comentado contempla igualmente que la redacción actual los casos en que el aborto fuese causado por la propia mujer, iguala en cuanto a su tratamiento punitivo a la mujer que consintiere que otro lo causare, consagrando en el último párrafo la no punibilidad de la tentativa de aborto de la mujer embarazada.

Además, sin brindar mayores explicaciones en la exposición de motivos, la Comisión redujo el monto máximo de la pena prevista de cuatro a tres años de prisión, no siguiendo en este punto los previsto en los Proyectos de 2006 y 2014, los cuales mantenían idéntica escala penal que la actualmente vigente. La Comisión refuerza la facultad discrecional del tribunal de juicio de dejar en suspenso la pena, ya consagrada como regla genérica para todos los delitos en el artículo 26 del Proyecto, agregando de manera novedosa la potestad del Tribunal de eximir a la

39 Creus, Carlos - Buomopadre, Jorge Eduardo, ob. cit., p. 74; Donna, Edgardo, ob. cit., p. 273.

$4^{\circ}$ Nuñez, Ricardo C. Tratado de Derecho Penal, cit., p. 181. 
mujer que practicó dolosamente su propio aborto, cuando los motivos que la impulsaron a cometer el hecho, su actitud posterior, su naturaleza y las demás circunstancias demuestren la inconveniencia de aplicarla.

De tal manera que la suspensión condicional del cumplimiento de la condena o, en su caso, su eximición se encuentra ligadas a un pronóstico de que la condenada no volverá a delinquir, no tornándose necesario un tratamiento penitenciario, como instrumento apto para la resocialización de la mujer (artículo 75 inc. 22 en vinculación con el artículo 5 inc. 6, Convención Americana sobre Derechos Humanos).

Los enunciados normativos que se proponen en el Proyecto de reforma para regular el aborto violento no intencional y para los abortos referidos a la actuación de la propia mujer mantienen como regla general la regulación vigente, intentando superar en lo que respecta al primero de ellos las diferentes posturas que se construyeron en orden a las exigencias subjetivas de la referida figura. En tanto que, en lo que atañe a los abortos referidos a la actuación de la propia mujer, la modificación se reduce a la menor escala punitiva del aborto doloso causado por la propia mujer y a la facultad que se le reconoce al Tribunal de juicio de eximir a ella de pena cuando el encarcelamiento se presente inconveniente, conforme a pautas similares para la suspensión de la ejecución de la condena.

En función de lo expuesto, en nuestra opinión, los textos del Proyecto en lo que respecta a los delitos analizados han intentado superar las críticas al Código vigente, aumentando -a su vez- la escala punitiva en el caso del llamado aborto preterintencional y disminuyéndola en el aborto doloso causado por la propia mujer resultan, por lo que las referidas modificaciones -en lo sustancial- deberían pasar el tamiz de la discusión legislativa sin dificultad.

\section{El aborto culposo y las lesiones a las personas por nacer ${ }^{41}$}

\section{III.1. El aborto culposo}

${ }^{41}$ Aporte elaborado por la Abog. Esp. María Marta Schianni. 
$\mathrm{El}$ art. 87 inc. 2 del proyecto establece: "Se impondrá prisión de seis (6) meses a dos (2) años y, en su caso, inhabilitación especial por el doble del tiempo de la condena a prisión, al que causare un aborto por imprudencia, negligencia o por impericia en su arte o profesión o inobservancia de los reglamentos o deberes a su cargo. El aborto imprudente causado a si misma por la mujer embarazada no es punible”.

Esta nueva figura viene a llenar el vacío legal que posee nuestro ordenamiento actual habida cuenta que existen diversas situaciones en las que un obrar imprudente, negligente o imperito, etc., puede producir como resultado la muerte de la persona por nacer.

De hecho, esta imprevisión legislativa fue contemplada por el anterior Proyecto del Código Penal elaborado por la Comisión creada a tales efectos mediante decreto PEN 678/12.

El derecho comparado da cuenta que esta figura tiene recepción en distintos sistemas jurídicos. Por caso, el art. 146 del Código Penal Español prevé pena de prisión de tres a cinco meses o multa de seis a diez meses, al que por imprudencia grave ocasionare un aborto. Asimismo, se establece una inhabilitación especial si el aborto fuere cometido por imprudencia profesional. Finalmente, al igual que el artículo nacional proyectado se exime de pena por este delito a la embarazada.

Por lo general, en la redacción actual del tipo de aborto quedan impunes aquellos casos de mala praxis médica, esto es, maniobras de negligencia por parte de profesionales de la salud que se dan con anterioridad al nacimiento de la persona humana. En efecto, los tribunales se han expedido sobre la ausencia de norma en este tipo de eventos del siguiente modo: "Ha quedado demostrado que no hubo comienzo de proceso de parto o nacimiento, sino que la operación cesárea se realizó una vez constatada la muerte de la niña, por lo que no existe sujeto pasivo de homicidio sino de aborto y, en la medida en que tal delito en su modalidad culposa no encuentra previsión normativa en el sistema argentino, la muerte de la 
niña antes de aquel proceso, aún de corroborarse una negligencia médica como pretende la querella, quedaría impune". ${ }^{42}$

En consecuencia, conforme nuestra legislación vigente, si la muerte del feto se produce en virtud del obrar imprudente o negligente del sujeto activo en etapas anteriores al inicio del nacimiento, por ejemplo, por asfixia intrauterina o prenatal, se evidencia la falta de configuración de la figura penal de aborto por atipicidad. No podemos soslayar que nuestro sistema jurídico-penal en materia de tipos culposos es de los llamados "numerus clausus", esto es, sólo la ley determina expresamente el elenco de conductas que pueden cometerse por negligencia, impericia o por inobservancia en los reglamentos o deberes a cargo.

Como el aborto culposo no integra ese universo de casos (sólo está prevista su forma dolosa o preterintencional), es que por imperio del principio de legalidad no cabe otra respuesta frente a estos supuestos que la impunidad. Esta problemática había sido advertida por Soler al expedirse sobre el aborto preterintencional: "No existe la figura del aborto culposo. Esto es sí no solamente en consideración a la estructura misma de este tipo de delito, sino que resulta evidente el hecho de que la ley no prevea expresamente la forma culposa, según lo hace en todos los demás casos, a falta de una definición general. Constituye un error afirmar que el art. 87 prevé un aborto culposo. Trátase de un delito preterintencional. El aborto sería culposo si el sujeto lo causara por sus violencias, pero sin que el estado de embarazo le constare o fuere notorio, así como se responde por las consecuencias culposas no ya cuando se debía saber lo que podía suceder. Además, esta figura, igual que las otras figuras preterintencionales, contiene un hecho base de carácter ilícito y doloso, por lo cual diferencia claramente de un delito culposo" 43.

Reiteramos, la disquisición relevante en este tópico consiste en que si se quita la vida de una persona después del nacimiento se comete un homicidio, en

42 Causa $\mathrm{n}^{\circ}$ 40.851/2015 - "S. R., M. S. s/ sobreseimiento - homicidio culposo"- CNCRIM y CORREC - Sala VII - 12/10/2016. En similares términos, causa no 9178/2013 - "M., C y otro s/ sobreseimiento" - CNCRIM Y CORREC - Sala I, 13/05/2015. 43 SOLER, Sebastián, Derecho Penal Argentino, Tomo III, Editorial TEA, 1976, Bs. As., p. 103/104. 
tanto que si se da muerte al sujeto pasivo antes del nacimiento se perfecciona típicamente el aborto. Esta clara diferenciación plantea el interrogante respecto al supuesto de hecho que se comete durante el nacimiento, lo que también redundará en el abordaje sobre la determinación del elemento típico "el otro" que exige la norma que castiga el homicidio.

También sabemos que la razón de ser de esta problemática cobró vigencia al derogarse la figura del infanticidio por intermedio de la ley 24.410. A partir del por entonces art. 81 inc. 2 del CP se perseguía penalmente al que mataba a la persona durante el nacimiento, razón por la cual la doctrina nacional postuló que esta frase del tipo derogado servía como pauta de interpretación para sostener que dar muerte a alguien en ese momento configuraría un homicidio.

En efecto, tomando distancia de la tesis civilista que requiere la completa separación del seno materno de la persona para poder adquirir el status jurídico de sujeto pasivo del delito de homicidio, la mayoría de los autores han sostenido que el nacimiento es un proceso que abarca distintas secuencias y que la protección de la vida humana independiente coincide con el comienzo del nacimiento, lo que ocurre con las contracciones expulsivas o con el comienzo de la primera incisión de la cesárea44. Creus y Buompadre afirman que basta que se mate al sujeto durante el nacimiento, por lo que este último es el momento a partir del cual estaremos en presencia de un homicidio y se da con el comienzo del parto lo que puede ocurrir con los primeros dolores que indican el comienzo del parto natural o, cuando faltan esos dolores, con el inicio del procedimiento de provocación artificial de aquél o de extracción quirúrgica del feto. 45

Entonces, el tipo penal proyectado por la Comisión viene a suplir el vacío legal que hoy tenemos en nuestro Código para aquéllas acciones u omisiones imprudentes o negligentes generadoras de un riesgo no permitido y que se

\footnotetext{
44 DONNA, Edgardo A., Derecho Penal Parte Especial, 2da. Edición actualizada, Rubinzal Culzoni, Santa Fe, 2003, tomo I, p. 19.

45 CREUS, Carlos- BUOMPADRE, Jorge Eduardo Derecho Penal Parte Especial,7a. Edición actualizada y ampliada, Editorial Astrea, Bs. As., 2007, Tomo I, p. 10.
}

\begin{tabular}{llll}
\hline \hline REVISTA FACULTAD DE DERECHO & NUMERO 3 & 2020 & Página 32 \\
\hline
\end{tabular} 
concreten en el resultado lesivo previsto por el tipo, esto es, que provoquen la muerte del feto dentro del seno materno.

Por último, cabe destacar que el precepto finaliza con la previsión de una excusa absolutoria a favor de la mujer embarazada que ocasione por alguna imprudencia o negligencia su propio aborto. Es sabido que las excusas absolutorias aluden a circunstancias que, una vez traspasados los filtros de tipicidad, antijuridicidad y culpabilidad de una conducta en la teoría del delito, eximen de pena al agente por razones de política criminal, dado que se propugna preservar un interés superior. En efecto, el delito como tal se encuentra perfeccionado, sin embargo no se obtendrá a partir de él ninguna consecuencia jurídica puesto que, al caer en el ámbito de la punibilidad, el legislador ha preferido por motivos de utilidad eximirlo de sanción.

En el particular, la razón de ser de la no punibilidad de esta conducta radica en el sufrimiento padecido por la madre a raíz del fallecimiento de su hijo provocado por su propio obrar imprudente, por lo que el castigo penal luce desproporcionado habida cuenta del daño moral que engendra tal pérdida.

\section{III.2. Lesiones a la persona por nacer}

El art. 95 del proyecto establece: "Se impondrá prisión de uno (1) a cuatro (4) años, al que causare a una persona por nacer una lesión o enfermedad que perjudique gravemente su normal desarrollo o provoque en él una grave afectación física, o mental".

Con el tipo penal proyectado se pretende salvar otra imprevisión legal que tiene nuestro Código Penal vigente consistente en los atentados hacia la integridad física y la salud de la persona por nacer.

Es que la doctrina mayoritaria se inclinó por excluir a la persona por nacer de la posibilidad de ser sujeto pasivo de las lesiones dolosas o culposas. No obstante, Creus y Buompadre han puesto en tela de juicio esta conclusión: "Muchos tratadistas excluyen al feto como sujeto pasivo posible de lesiones: sólo estaría 
protegido de aquellas lesiones que le produjeran las maniobras abortivas a través del delito de aborto tentado, cuando el agente obró con la finalidad de darle muerte; esta tesis restrictiva excluye de la punibilidad las hipótesis -que no dejan de ser posibles en la realidad- de las lesiones causadas al feto en el seno materno sin intención de darle muerte (p.ej., administrándole a la madre específicos que lo deformen). Sin embargo, parece que es hora de revisar estas restricciones, porque aquí el otro puede ser el feto, ya que la ley no nos pone en la necesidad de distinguir sujetos pasivos distintos de una misma acción, como ocurre con la de matar, que contempla conjuntamente los tipos de homicidio y de aborto". 46

Es un delito de resultado, que puede ser cometido por cualquier medio, incluso puede adoptar la configuración de comisión y de comisión por omisión u omisión impropia siempre que, claro está, el sujeto activo se encuentre en posición de garante de la persona por nacer (vgr. el médico obstetra que debe velar por el bienestar físico y la salud del feto).

Tal como surge de la descripción del tipo, para cometer este delito no se contempla cualquier clase de lesión, habida cuenta las especiales características que posee el sujeto pasivo. A diferencia, de lo que ocurre con las lesiones previstas en los arts. 89, 90 y 91 en las que se sanciona en forma escalonada de acuerdo a la gravedad del daño provocado en el cuerpo o la salud de una persona, en el tipo bajo estudio se vulnera a la persona por nacer, a la integridad física y salud de una vida humana alojada aún en el seno materno, dependiente. Por ello, se exige la comprobación de una lesión o enfermedad (proceso patológico que exige cura) que perjudique gravemente su normal desarrollo, su paulatino crecimiento y avance para alcanzar la independencia fuera del seno materno. Además comprende aquellas maniobras que lo afecten física o mentalmente en forma grave. Estos elementos normativos de carácter científico, serán establecidos en el caso concreto con el auxilio de la ciencia médica.

Acudiendo nuevamente al derecho comparado, más precisamente en la legislación penal española, encontramos una disposición similar. Así, el art. 157 del

46 CREUS-BUOMPADRE, ob. cit. p. 78/79.

REVISTA FACULTAD DE DERECHO

NUMERO 3

2020

Página 34 
Código Penal Español reza: "El que por cualquier medio o procedimiento, causare en un feto una lesión o enfermedad que perjudique gravemente su normal desarrollo, o provoque en el misma una grave tara física o psíquica, será castigado con pena de prisión de uno a cuatro años". También el citado ordenamiento prevé en su art. 158 la forma culposa de este delito, y deja impune las lesiones culposas que ocasione la embarazada a la persona por nacer.

El artículo 96 del proyecto contiene la figura culposa del delito en cuestión, imponiendo una pena de prisión de seis (6) meses a dos (2) años o de seis (6) a veinticuatro (24) días-multa, al que por imprudencia o negligencia, impericia en su arte o profesión, o inobservancia de los reglamentos o deberes a su cargo causare la lesión o enfermedad del artículo 95.

El art. 97 prevé: "Las lesiones a una persona por nacer causadas por la mujer embarazada no son punibles".

A diferencia del Código Penal Español que sólo exime de pena a las lesiones culposas ocasionadas por la embarazada al feto, preservando el ius punendi hacia las dolosas, en el proyecto que analizamos se adoptó la postura de dejar impune tanto las lesiones dolosas como las culposas provocadas por la madre a su hijo. Esta cláusula constituye una excusa absolutoria, que integra al ámbito de la punibilidad, y pueden esgrimirse dos razones de política criminal por las cuales se adoptó esta postura.

Por un lado, en el caso de las lesiones dolosas la lógica y la experiencia indica que pueden provenir de maniobras abortivas frustradas por parte de la mujer embarazada hacia la persona por nacer, razón por la cual con la exclusión de la persecución penal de estas conductas se pretende evitar futuros intentos por parte de la agente.

A mayor abundamiento, podría trasladarse la misma justificación que sustenta la impunidad de la tentativa de aborto de la mujer. Si los atentados contra la vida de la persona por nacer intentados por la embarazada quedan eximidos de pena, luce razonable que el menoscabo a la integridad física y salud corran la misma suerte. 
De otro costado, la impunidad de las lesiones culposas puede encontrar fundamento en las razones expresadas al considerar el aborto culposo ocasionado por la mujer embarazada, es decir, mitigar el sufrimiento o angustia que produce haber provocado un menoscabo en la salud del propio hijo por su accionar imprudente o negligente, vale decir sin intención. 